\title{
Pioneers of Social Research: A Life Story Interview Collection
}

\section{Social and Behavioural Sciences}

Camille Corti-Georgiou

University of Manchester, UK

camillegeorgiou@hotmail.co.uk

\begin{abstract}
The Pioneers of Social Research, 1996-2018 is a rich qualitative collection of life story interviews with over fifty pioneering academics, who are regarded as having played a significant role in developing the practices of social research across key disciplines. The project was directed by Paul Thompson, himself a pioneer of oral history in Europe. The interviewees are essentially British pioneers, all but six born within what was then the British Empire, but they worked worldwide in Europe, Africa, Australasia, the Caribbean, Latin America and the United States. The collection includes full interview transcripts and detailed summaries, YouTube playlists, thematic highlights and associated teaching resources, all openly accessible through the UK Data Service. The following data paper provides an overview of Thompson's data collection approach, the archiving and publishing of the data materials, and a discussion of the resources available. It also highlights opportunities of this unique research data for future use.
\end{abstract}

\section{Keywords}

qualitative research methods - qualitative data - life story interviews - Sociology anthropology - statistics - politics - pioneer

- Related data set "Pioneers of Social Research, 1996-2018" with DoI www.doi. org/10.5255/UKDA-SN-6226-6 in repository “UK Data Service”

(C) CAMILLE CORTI-GEORGIOU AND PAUL THOMPSON, $2019 \mid$ DOI:10.1163/24523666-00401008

This is an open access article distributed under the terms of the CC-BY 4.0 license. 


\section{Introduction}

The Pioneers of Social Research, 1996-2018 is a rich and in-depth qualitative collection of over fifty life story interviews with eminent academics and scholars who played a role in shaping social research as we know it today. The interviewees are essentially pioneers of British social research, all but six born within what was then the British Empire, but they worked worldwide in Europe, Africa, Australasia, the Caribbean, Latin America and the United States. While most were sociologists and anthropologists, some worked the fields of economics, geography, political science and statistics. They include the leading anthropologists Raymond Firth, Jack Goody and Mary Douglas, the sociologist and social policy campaigner Peter Townsend, the quantitative sociologist John Goldthorpe, the feminist social researcher Ann Oakley, the French life story leader Daniel Bertaux and the American life course school initiator, Glen Elder.

Leading oral historian, Paul Thompson, now Emeritus Professor of Sociology at the University of Essex, led the Pioneers of Social Research study, a culmination of twenty-one years of fieldwork. Thompson himself recorded 45 of the pioneers, wholly or in part, while colleagues carried out other interviews. Each interview is rich in content and delves into the full life of the interviewee, covering family background, upbringing and detailed accounts of their own major projects.

The Pioneers of Social Research, 1996-2018 is a qualitative data collection which is archived jointly at the UK Data Service and the British Library and includes full interview transcripts, interview summaries, biographies, thematic highlights, selective playlists of audio excerpts on YouTube and associated teaching resources (Thompson, 2019). These resources serve both as biographical accounts of key researchers and weave a tapestry of significant topics, themes and issues in social, political and cultural history that are still pertinent in social science today, such as gender, kinship, ethnicity and methods of research. The interview collection is of unique value presenting rich opportunities for exploring the development of social research from the mid-2 $0^{\text {th }}$ century to the present.

\section{Background}

Between 1940 and 1970, social research as a discipline witnessed an unprecedented flourishing in the UK. This period saw a proliferation in the spread of themes and geographical span of research undertakings, creating a cornerstone 
for future developments in social research. Projects such as Margaret Stacey's Tradition and Change: a Study of Banbury (1960) and Peter Townsend's The Last Refuge (1962) and Poverty in the United Kingdom (1979), were conducted on a scale and with a methodological diversity that could not be repeated today. Thompson's campaigning to rescue the fieldwork materials and data from important earlier social research projects, which were typically lost on the retirement or death of the original researcher, resulted in 1994 in the establishing a national Qualitative Data Archival Resource Centre (Qualidata) funded by the UK's Economic and Social Research Council (ESRC), to search for and rescue such earlier data. Once Qualidata had begun this rescue mission, and classic examples of earlier British social research were being located and archived, thus it seemed potentially rewarding to record life story interviewers with some of the project researchers (Thompson \& Corti, 2004). The first was a marathon 17-hour interview with Peter Townsend begun in 1997.

\section{Thompson's Interviewing Approach}

The informants for this project were selected on the basis of a number of factors. First was the limitation of the budget available to conduct and prepare interviews for publishing. In discussion with colleagues within the broader UK social science community, it was agreed that the project should seek to record around fifty interviews with leading academics who had worked in the Anglophone research space. The target sample aimed for a balance of men and women, disciplinary background and approach, covering both qualitative and quantitative traditions. Around seventy individuals were nominated, some of whom could not be traced or were unavailable, some had already been interviewed about their work for other projects, and others declined due to ill health.

Adapting his own distinct and well-practised method to record life histories using the life story method of interviewing, first utilised in research such as The Edwardians, Thompson's interviews with academics served to explore the pioneer's micro-historical experiences within a macro-historical framework, exploring their social, personal and intellectual contexts (Thompson, 1975 and 2017). Thompson (2004) observes that:

The information obtained from life-histories challenges the researcher to understand an individual's current attitudes and how they may have been influenced by initial decisions made at another time and in another place. Although the researchers' life story interviews were recorded 
primarily to explain the milieu of their own research, the biographical accounts proved particularly rewarding in exploring how the interviewees' research interests and practice have been shaped by society, family, feelings and experiences. Tracing their remarkably acute social observations, one is exposed to the Pioneer's own life contexts, such as social class, upbringing, schooling and interactions with influential figures, and how that could have generated or inspired their key research concerns.

Thompson believes that trying to position his own approach within the field of historiography of social science in the $20^{\text {th }}$ century is difficult. Several of the Pioneers grew up in a 'colonial bubble', and for Thompson this period of contemporary British social history lacks good methodological discussions (CortiGeorgiou, 2019). He contrasts two histories of the period: the Oxford-centred parochialism of Chelly Halsey's A History of Sociology in Britain (2004) against the international and interdisciplinary vision of Eric Hobsbawm's The Age of Extremes: The Short Twentieth Century, 1914-1991 (1994).

Using their own words, their own timelines, with some guidance from the interviewer, the pioneers offer thorough, personal narratives of their lives. As Thompson observes, these memories include much crucial information about their backgrounds and the genesis and practice of their research; and the influence of parents, teachers, and academic colleagues. Indeed, remembered evidence can often tell us more than a document from the time. Equally, it is important to evaluate retrospective oral evidence like any other historical material in the context of other relevant evidence (Thompson, 2017). In the case of the Pioneers, where basic facts can be checked, they can most often be confirmed.

Thompson also stresses the importance of understanding that the suppression of memories too painful to tell, or of how recollections can be transformed in retrospective telling, is in itself crucial evidence of changing social values and the interviewee's sense of personal identity. Thus Thompson (2004) notes that the life story method not only provides crucial evidence of practice, but:

Differentiating this method from general qualitative interviewing is the notion that is not about whether or not what the interviewee is saying is true, but rather, how they are remembering it. The pioneers' life stories are horizontal; in essence, it is what they won't say, what they forget, the silences of memory and the transformations that take place in their memories. It is about being interested in the forms of narrative and presentation. 


\section{Collecting the Data}

The interviewing style for Pioneers generally follows a chronological path, beginning with childhood and proceeding sequentially to the present, and covering a set of core themes, summarized in a topic guide (Figure 1). Over the course of the twenty-year fieldwork period, the recording equipment changed from analogue to digital, but in all cases a high-quality Marantz recorder was used.

In the cases where Thompson did not record the interviews himself, he chose colleagues who were experienced researchers in the qualitative tradition to record the pioneers. Interviewers were fully briefed on an individual basis by Thompson on the particular interview approach and were instructed to follow the topic guide for the study. Following the first interview, Thompson read the transcript and commented on areas he felt were missing and should be further explored in a follow-up interview.

The recordings were all transcribed by a professional transcriber who had been working for Thompson for over 30 years, and who was familiar with his transcription protocol. Pauses, laughter and interruptions were all documented. Thompson typically made the first edit to make the text coherent, for example to remove repetitions. These edits were then given to the interviewee to appraise; sometimes material was removed or reworded by the Pioneer, but the main aim was to keep to the original narrative as close to the original as possible. Any slanderous or libellous comments were redacted.

Initially, those interviewed for the project were solely individuals whose fieldwork was being archived by Qualidata. Subsequently, the range of pioneers included in the study was broadened, with researchers from a wider array of disciplines introduced into the project. In particular, more interviews were carried out with quantitative and survey researchers and special efforts were made to include women researchers and researchers from minority ethnic backgrounds. For some pioneers, interviews were carried out in one sitting of up to three hours recording, while others spanned multiple recording sessions. For example, Colin Bell's interview spanned across six sittings and over two years. In Paul Thompson's own case, a supplementary interview was also conducted some years after the initial interview. With Marilyn Strathern, the interview was recorded as a supplement to an original interview with her Alan Macfarlane's Cambridge Thinkers series (MacFarlane, 2009). The Pioneers' interviews sometimes exceeded 15 hours, such as in Peter Townsend's case whose interview required remarkably little editing, reflecting Townsend's exceptional ability to recount a coherent narrative. 


\section{Pioneers of Social Research: Interview Guide}

Pre-interview

Look for an outline biography of cv of the person you are recording (Wikipedia, Who's Who, or they may send you a cv)

Try to give a hard look at what seem to be the researcher's key books.

\section{For every interview it is essential to establish in the early part:}

a) the date and place of birth of the interviewee, their family background and occupations;

b) what led them towards research and university work;

c) what were they key influences in leading them towards their pioneering research themes.

\section{Opening questions}

- Date of birth, family and own occupations.

Can we begin by talking about your family background and early life, and any early influences, which may have led you towards university work?

\section{FAMILY AND EARLY LIFE}

- Memories of family background and grandparents: were they an influence?

- Parents - where they came from, their jobs, their characters, could you talk to them, were you close to them;

- Education - school and University: important friendships and influences

- Youth - important friends and their influences; what you did in National Service

\section{PIONEERING RESEARCH}

- Main research interest - how you got into it, describe what it was:

Go through the sequence of main projects and books

- With each, ask what was the objective, what were the difficulties

- When there was fieldwork, ask for a detailed account of how it went: types of contacts (insider or (colonial) outsider? especially for work overseas), types of samples and interview, participant observation etc.

- What documents were kept (and could be archived)

Sometimes I think in this section you can risk debating a little, to clarify the researcher's position

- What would you say is the key contribution, which you have made?

\section{WORKING CAREER}

* First job - why you chose it

- Other early jobs and then main jobs - why and how; did you plan a career, or find it by chance

* Describe your work role;

- Do you remember some of the people you worked with - important influences at work, friends and enemies - can you tell us something about them?

- Social life connected with work.

\section{LATER FAMILY LIFE AND LEISURE}

- Whether single or married; if married, how you met your husband or wife, their background, jobs;

- Children - ideals of parenting, hopes and ambitions for children

* Leisure and hobbies - what have been your main enthusiasms outside work

- Friends how important have friends been to you? Have any been special influences?

- Later life - how do you see your focus in or approaching retirement: continuing research and writing, or new activities, becoming grandparents?

\section{Closing questions for all interviews}

- Looking back on your working career, in your work, what you are most proud of?

- Summing up your life as a whole, what have been the worst and the best things?

FIGURE 1 Topic Guide for the Pioneers interviews

UK DATA SERVICE, SN6226: PIONEERS OF SOCIAL RESEARCH, 1996-2018

RESEARCH DATA JOURNAL FOR THE HUMANITIES AND SOCIAL SCIENCES (2019) 1-18 


\section{The Data Collection}

- Pioneers of Social Research 1996-2018 deposited at UK Data Service DoI:www.doi.org/10.5255/UKDA-SN-6226-6

- Pioneers of Social Research

- YouTube channel - URL: www.youtube.com/channel/UCmKımj5dCqo XuCWI7DVKx2w

- Collection of interview summaries - URL: http://discover.ukdataservice. ac.uk/QualiBank/?f=CollectionTitle_Pioneers

- Teaching resources - URL: www.ukdataservice.ac.uk/teaching-resources/ pioneers.aspx

- Temporal coverage: $1996-2018$

The interviews themselves generated a vast amount of high-quality qualitative data, which took a great deal of time to both record and to document and analyse. Cognisant of the desires and requirements of users of the data, who may or may not have prior knowledge of the particular pioneer, Thompson undertook the task of contextualising the interviews through creating new documents: condensed summaries and thematic highlights, selecting which parts to emphasize and which to omit. By drawing out significant themes from the narratives, he also included descriptions of how particular events, such as their family environment or a meeting with an older researcher, would go on to influence their opinions and future research decisions.

The interviews were conducted under consent and copyright practices prior to the GDPR. Interviewees were initially approached through a letter seeking permission to record them and archive their recordings and documentation at the British Library and Qualidata, later becoming part of the UK Data Service. Thompson retains his copyright in the audio and the associated newly created documents, but the intention was always to provide open access for other researchers. More recently the Data Archive set has been made available under a Creative Commons license. At the end of the original recording sessions, the interviewees completed forms transferring the copyright in their words to the British Library, to secure the permanent sound archiving of the collection. Versions of this participation and copyright transfer form, covering long-term archiving, are shown in Figures 2 and $2 a$.

The collection was submitted to the UK Data Service, where standard Data Archive processing activities were undertaken for qualitative data collections (UK Data Archive, 2015). Each interview was read through, redacted where needed for online publication, and formatted into a rich text format template (Figure 3). 


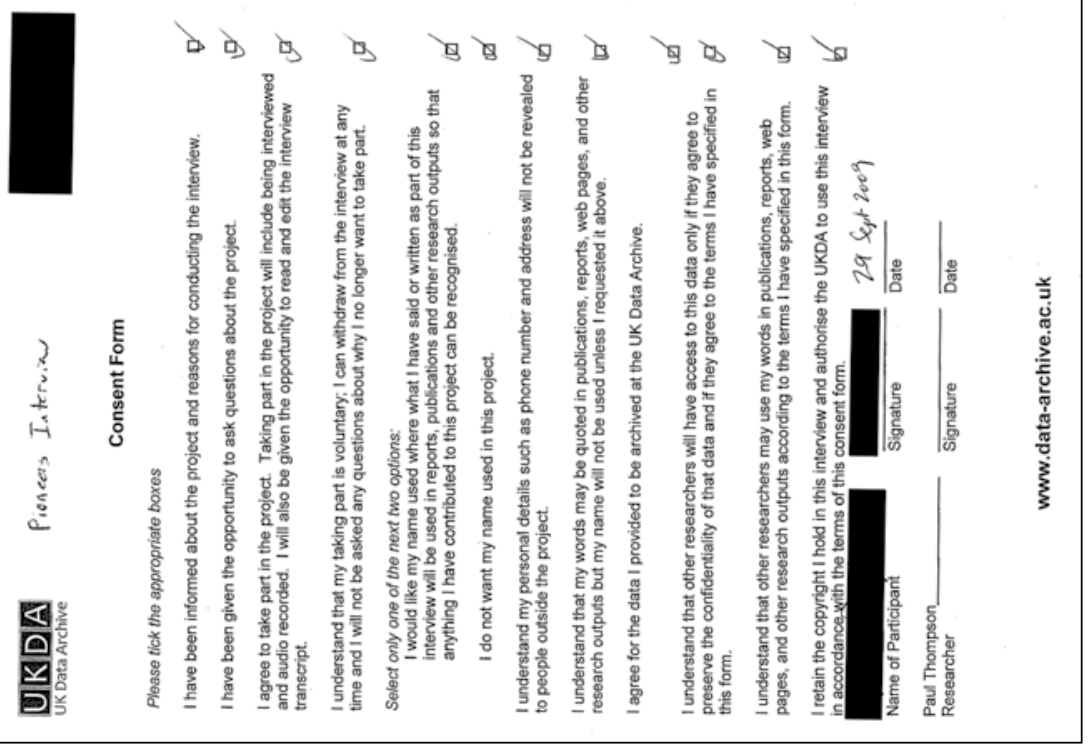

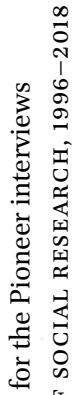

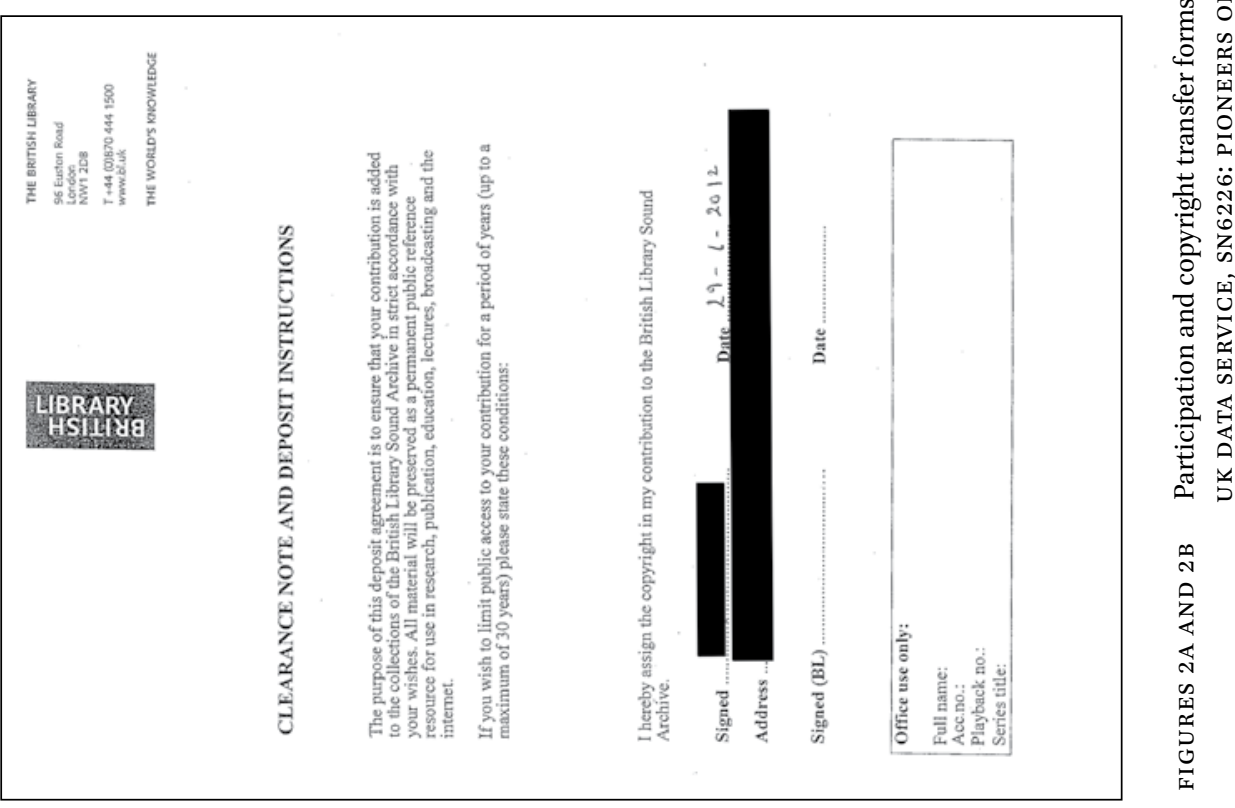




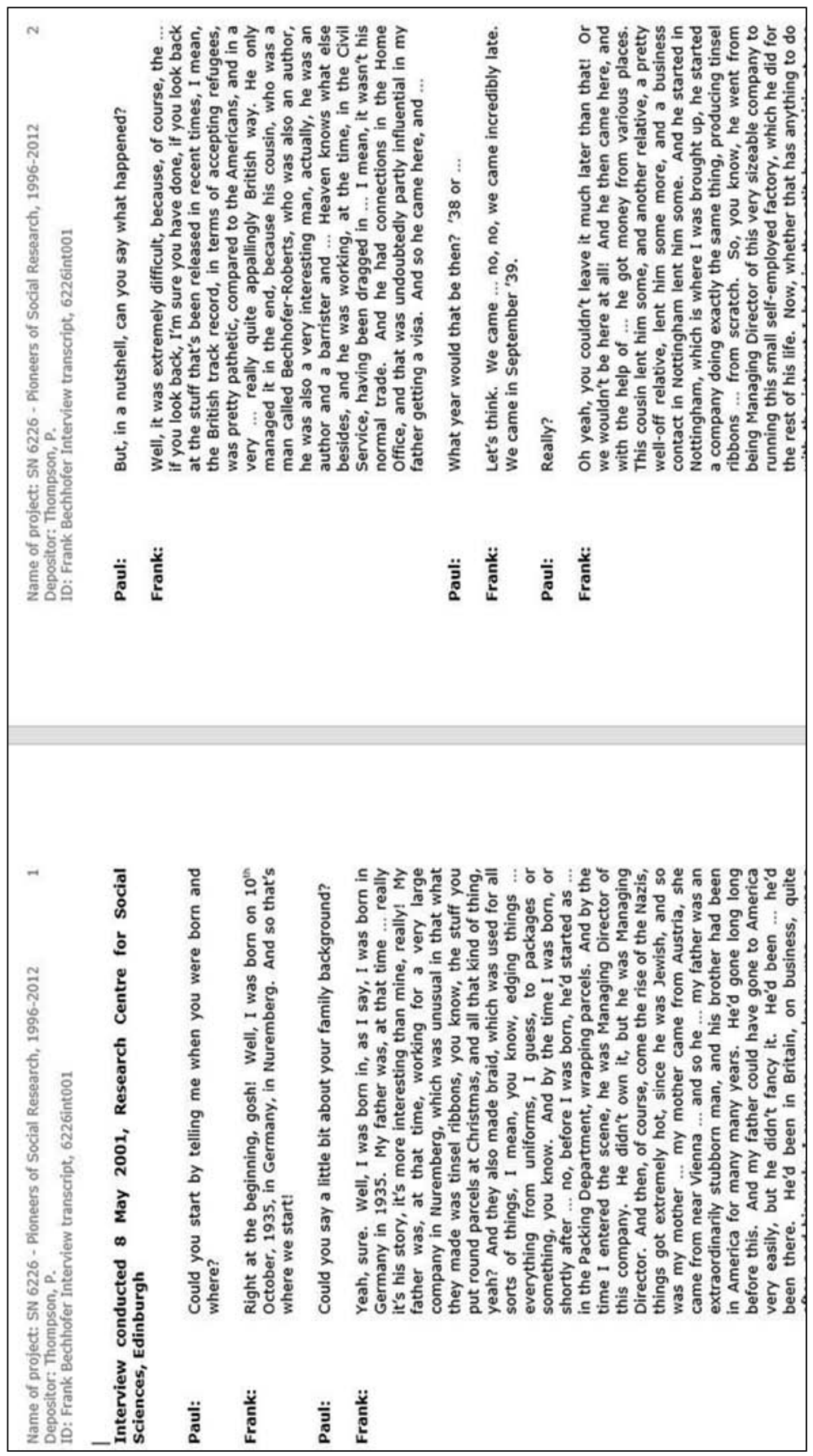

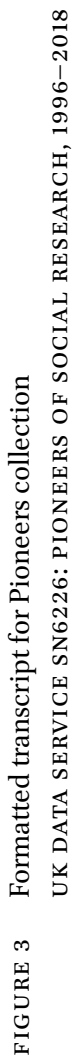


The interviews are made available as a zip bundle along with a public-facing catalogue record, a data list and associated documentation, such as the topic guide. Figure 4 shows the catalogue record, structured according to the de facto social science metadata standard, the Data Documentation Initiative (DDI). Figure 5 displays the interview collection's data list.

The interviews were then further processed and each marked up into XML format for publishing to the UK Data Service's online data browsing facility, QualiBank. Transcripts of each interview are thus freely available, to download as part of the Pioneer of Social Research, 1996-2018 collection itself, and as an online resource. To enhance the usability of these transcripts, a bespoke citation tool has been included as a feature in QualiBank, to enable persistent identification and resolution of user-selected extracts of the interview. Users

Pioneers of Social Research, 1996-2018

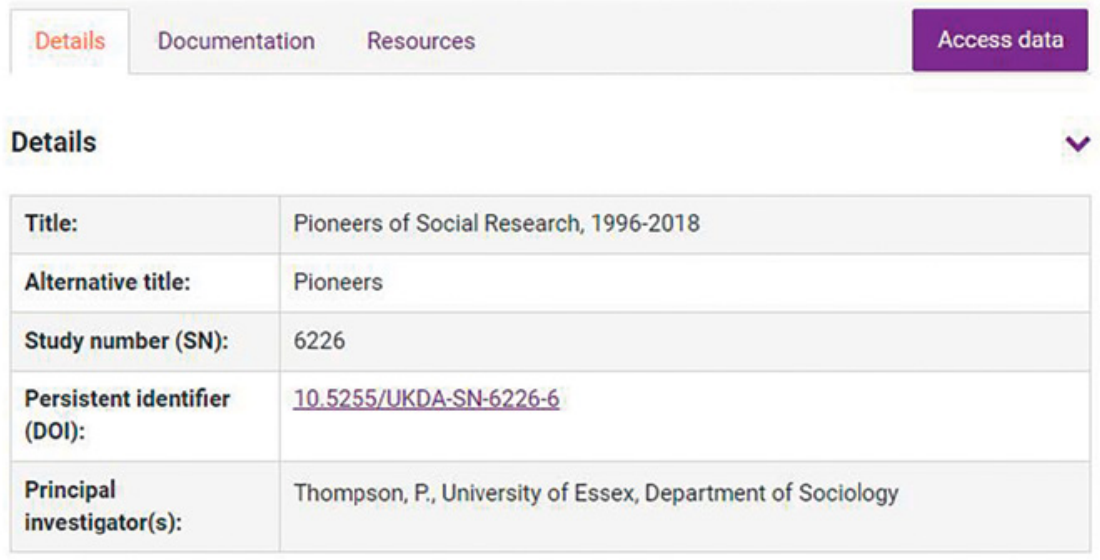

\section{Sponsors and contributors}

\section{Citation and copyright}

The citation for this study is:

Thompson, P. (2019). Pioneers of Social Research, 1996-2018. [data collection]. 4th Edition. UK Data Service. SN: 6226, http://doi.org/10.5255/UKDA-SN-6226-6

FIGURE 4 Catalogue record for the Pioneers of Social Research, 1996-2018 collection (SN6226) UK DATA SERVICE SN6226: PIONEERS OF SOCIAL RESEARCH, 1996-2018 


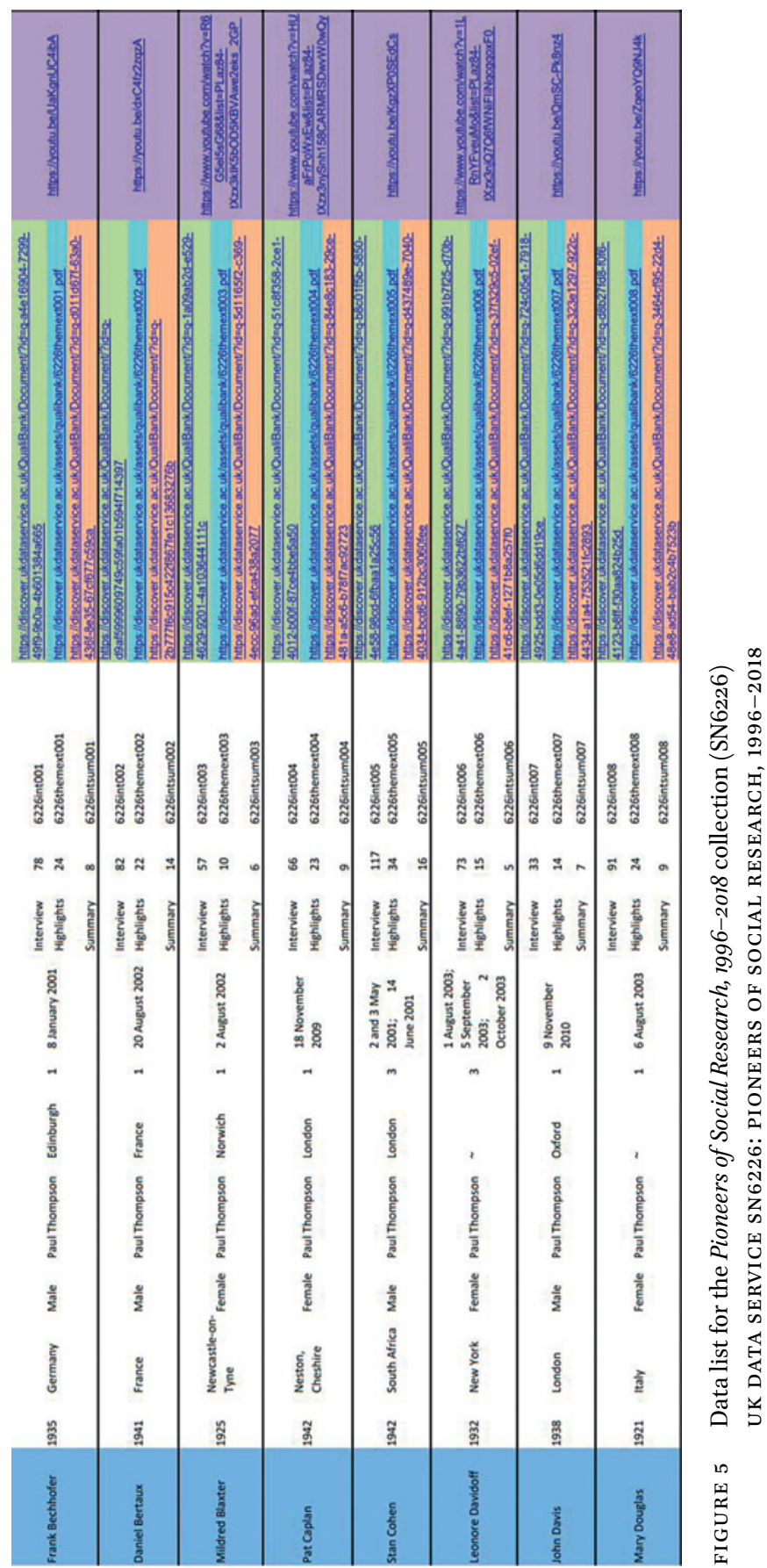




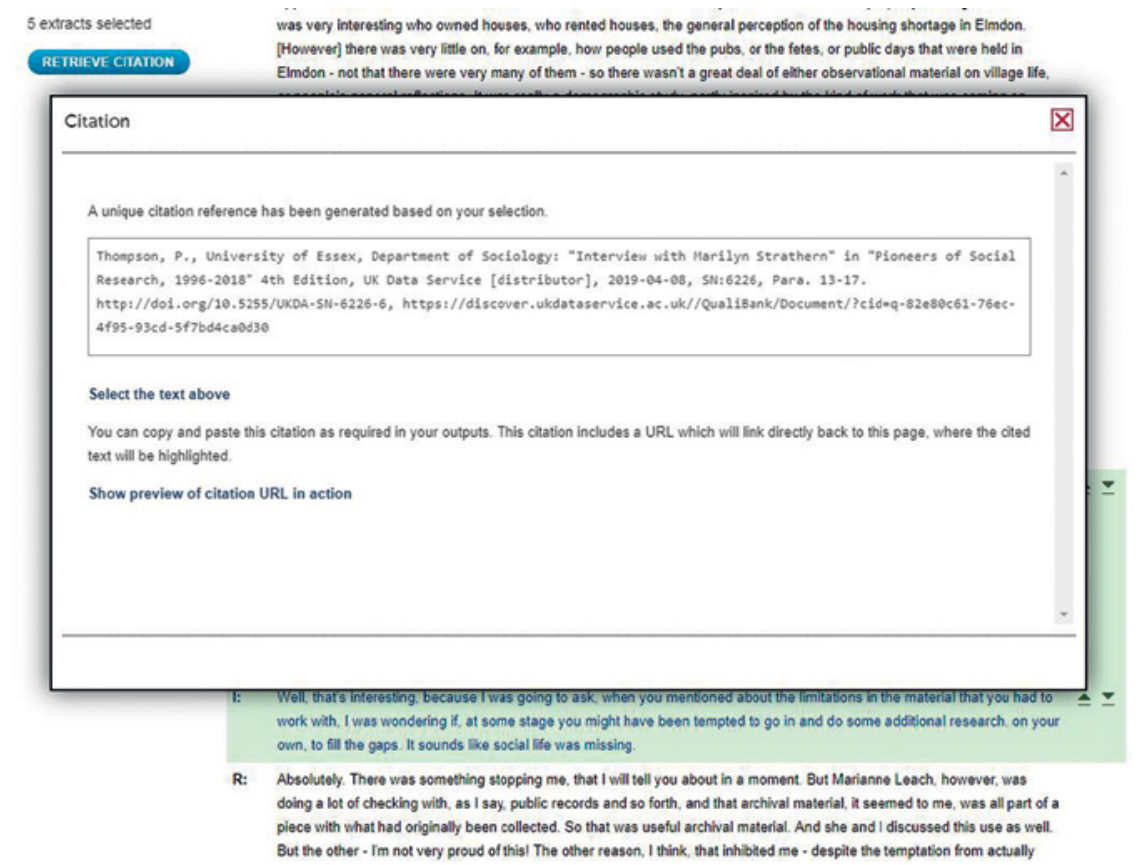

FIGURE 6 Citation facility in Qualibank, displaying citation for a selection of Pat Caplan's interview

UK DATA SERVICE SN6226: PIONEERS OF SOCIAL RESEARCH, 1996-2018, QUALIBANK

can cite specific paragraphs or selections of text and a tailored persistent citation is created for them, which can be used in subsequent publications when referring to the quote (Corti \& Fielding, 2016). Figure 6 shows this tool working to create a citation for a selected paragraph of Pat Caplan's interview.

\section{Audio Extracts}

One of the most interesting and novel characteristics of the Pioneers collection is its associated YouTube channel. This qualitative collection is the first at the UK Data Service to have its open data stored and shared via YouTube. As the full interview audio files are extremely large and difficult to stream, a set of audio extracts (from 3 to 10) were chosen by Thompson to offer a glimpse into the individual's key contributions to social research. While the full audio files are available on request as wav or mp3 files, the extracts allow for a snapshot 
of the Pioneer's life story, shedding light on their personality and concerns and key highlights of their interview.

Audio clips were prepared, edited into mp4 videos using Lightworks film editing software, and collated into playlists for each individual pioneer. These videos were then uploaded to a YouTube channel dedicated to the Pioneers project (as in Figure 7). Subtitles were embedded into each video to allow for more enriched and comprehensive watching, and photographs of the pioneers, often pertaining to the extract theme in question, were included in the videos. Each pioneer has their own playlist, with a series of extracts offering a snapshot of their full life story interview, as shown in Figure 8 for Peter Townsend.

Finally, each video was marked with appropriate tags for better identification through YouTube and a description prepared, providing links to:

- their complete YouTube playlist;

- their full interview transcript via Qualibank;

- the full archived Pioneers collection (SN6226); and

- their browse page on the teaching resource (described below).

The aim of these playlists is, first and foremost, to provide users with a preview of the pioneer's full interview, without having to access the full audio file. However, from a data storage perspective, YouTube also offers a reliable way to hold and share open data on an external site, resulting in less maintenance, storage and delivery constraints for a data service, for whom audio streaming is not the main feature.
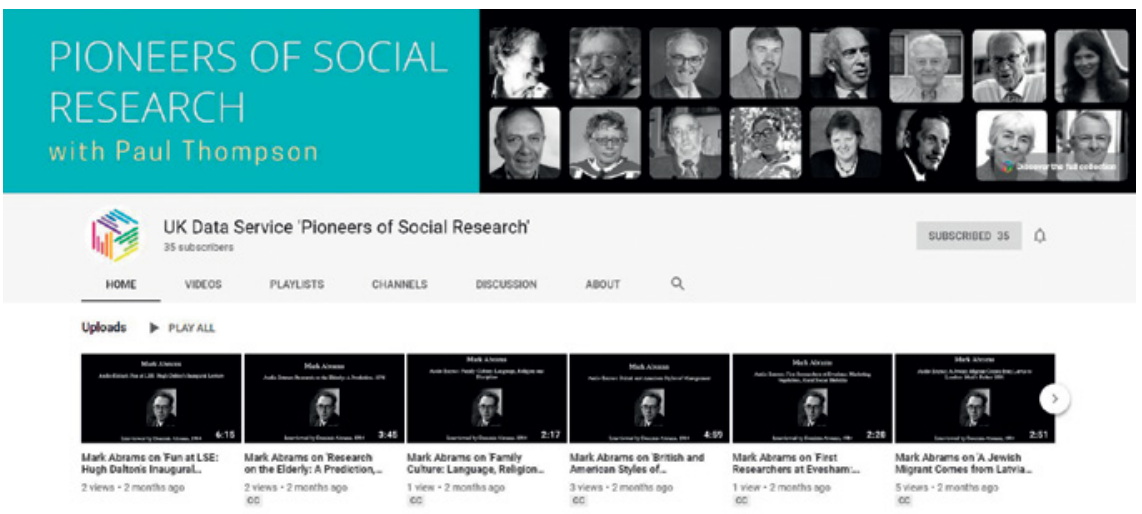

FIGURE 7 Pioneers of Social Research YouTube Channel YOUTUBE, WWW.YOUTUBE.COM/CHANNEL/UCMK1MJ5DCQOXUCWI7DVKX2W 


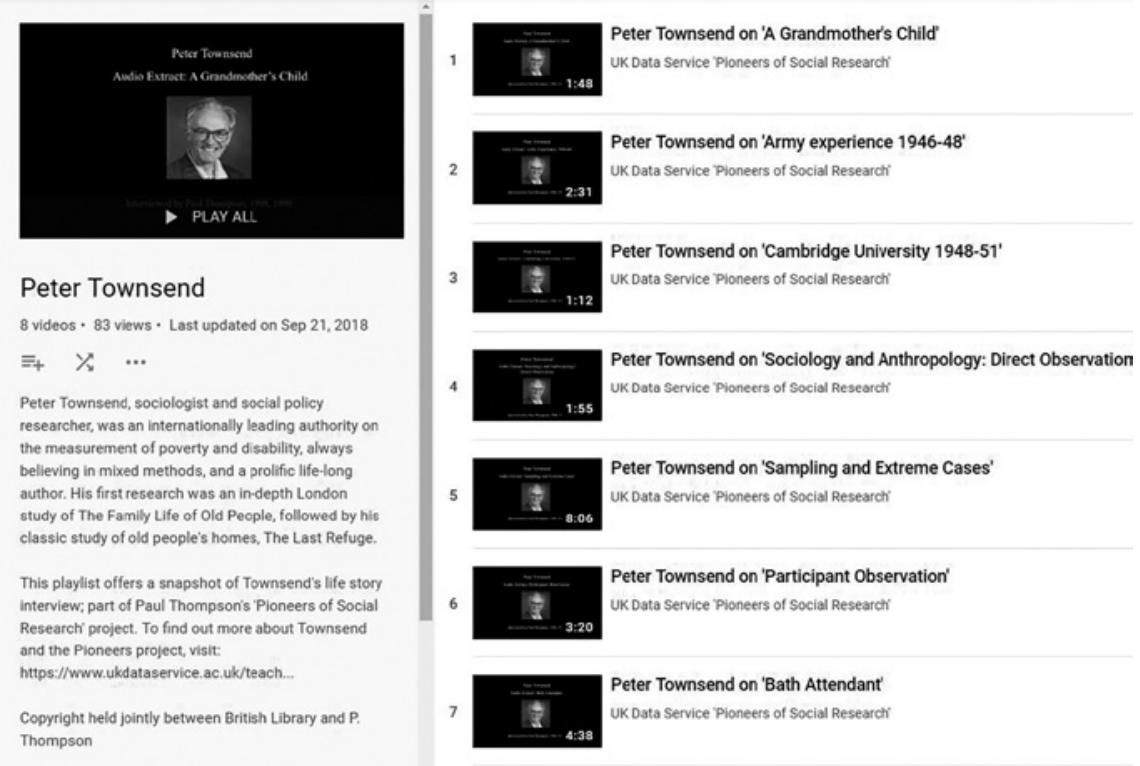

FIGURE 8 Example of Pioneer's playlist: Peter Townsend YOUTUBE, WWW.YOUTUBE.COM/PLAYLIST? LIST=PLAZ84

-TXZX3KMIISVGATJYRDPESZ8IL2C

\section{Teaching Resources}

To further encourage use of the dataset and to add pedagogical value, a suite of teaching resources pages were created for the UK Data Service website (Morgan-Brett, 2014). A range of worksheets and activities were developed to aid in the teaching of selected, prominent themes such as 'Poverty and inequality', 'Women and social research' and 'Pioneering research methods'. For each theme, interview extracts were selected that explored the theme through a piece of research undertaken by the pioneer. For example, in the case of 'Poverty and inequality', an extract from Townsend's interview is selected, where he discusses his celebrated study, The Last Refuge (1962), with questions posed surrounding his observations and learning points from the study. Each pioneer has their own page, with a photograph, short background, their main approaches to research, most notable publications and links to their interview, summary and YouTube playlist (as shown in Figure 9). Users can browse through the Pioneers using filters on attributes and characteristics such as field, gender or research approach. 


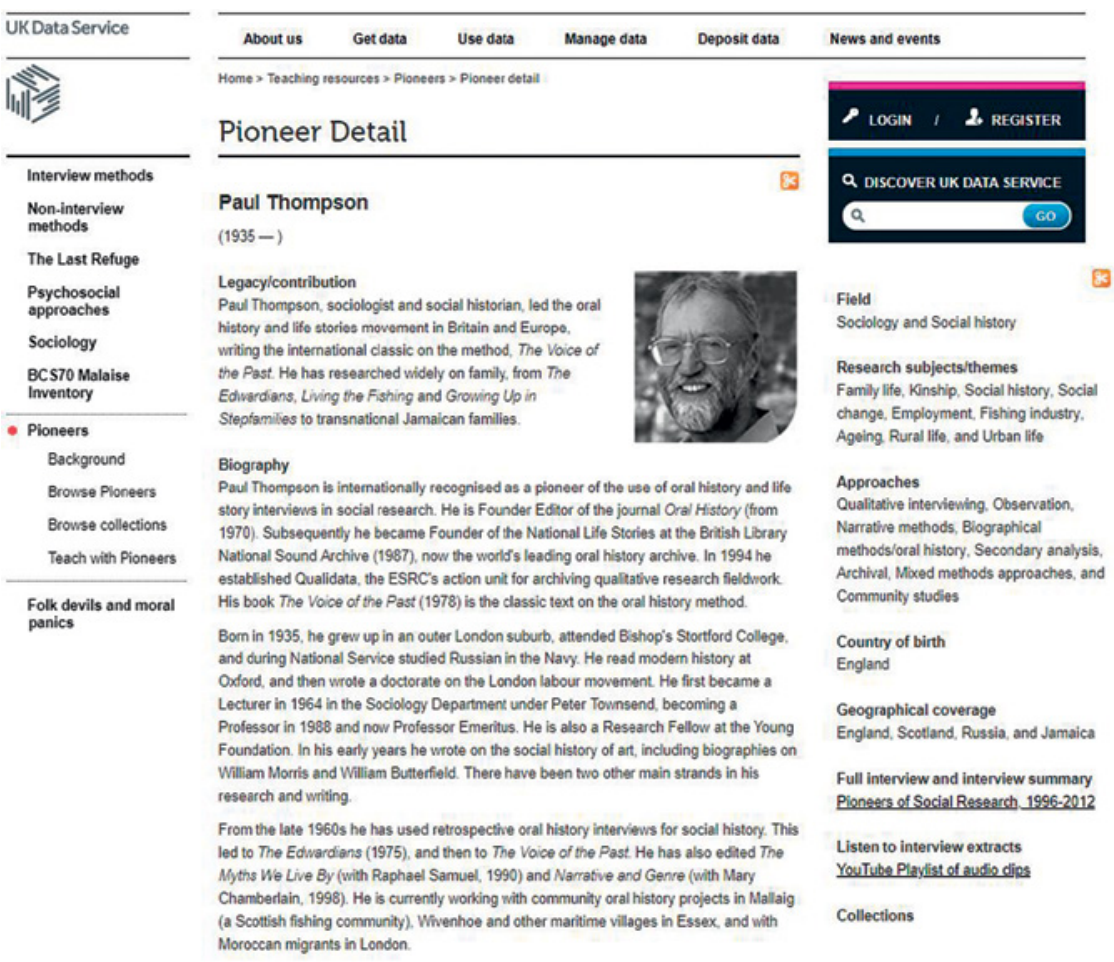

FIGURE 9 Paul Thompson's individual browse page on the Pioneers Teaching Resource UK DATA SERVICE, 2019

\section{Conclusion and Future Use of Data}

The Pioneers of Social Research, 1996-2018 is a unique and unrivalled data collection. The collection of life stories enables the exploration and identification of dominant narratives of the lives of some of the most eminent British scholars, within the events and situations that have shaped the field of social research. As of spring 2019, Thompson and colleagues from the University of Essex were completing a book using the whole interview set along with the documentary resources described in this paper hosted on the UK Data Service website (Thompson, Plummer \& Demireva, forthcoming).

Other scholars have already started to reuse the interviews to revisit research and dominant methodological approaches of the 1960s and 1970s (Savage, 2005; Elliot \& Lawrence, 2016). Further future use of the dataset is boundless with opportunities for supporting historical research on the development of research methods across the social sciences, and inspiring early career researchers, 
offering them models and encouraging them to develop new ideas from social observations and experiences. Indeed, Thompson (2000) as a leading advocate and pioneer of qualitative data sharing reflects:

There are, in short, many very important gains from re-analysis. At the start of a research project, it can be invaluable in providing a sense of the topics, which can be successfully covered in interviewing, and therefore make the pilot stage of the new project both more effective and also much swifter. At a later stage a comparable interview set may also provide a crucial wider sample base for testing the interpretations that are emerging. Finally, by making your research data available to re-analysis by others, you may strikingly multiply the outcomes from your research through the publications of others from the same material which you have created.

\section{Acknowledgements}

Many thanks to Paul Thompson for creating the study data itself along with the value-added materials, such as the potted biographies, summaries and the thematic extracts; and for allowing the author the opportunity to work on the archiving of, and describe his unique collection. And thank you to staff and ex-staff at the UK Data Archive, namely Ole Wiedenmann, Maureen Haaker, Libby Bishop, Bethany Morgan-Brett, Darren Bell and Louise Corti for their input into various data preparation and publishing activities over the past few years. Finally to Rob Perks at the British Library for many years of support for curating national life stories.

During the period of creation of this set of interviews, Paul Thompson was a Professor of Sociology at the University of Essex, and from 2008 an Emeritus Professor working as a volunteer. Initial funding was secured from the University of Essex while subsequent funding support came from the Fuller Bequest, the British Academy (2009-11), and most recently the Leverhulme Trust (201618). The Economic and Social Research Council (ESRC) provided the funding for Qualidata, and then later the UK Data Service, through which the data were prepared, curated, published and archived.

\section{References}

Bell, C. (2004). Doing sociological research: the genre of "owning up". International Journal of Social Research Methodology, Theory and Practice, 7(1), 29-33. 
Corti, L., \& Fielding, N. (2016). Opportunities From the Digital Revolution: Implications for Researching, Publishing, and Consuming Qualitative Research. SA GE Open, 6(4). DOI:10.1177/2158244016678912.

Corti-Georgiou, C. (2019). Short unpublished note from interview with Paul Thompson on his interview approach and context, 20 June 2019.

Elliott, J., \& Lawrence, J. (2016). The Emotional Economy of Unemployment: A Re-Analysis of Testimony From a Sheppey Family, 1978-1983. SAGE Open. DOI:10.1177/2158244016669517.

Halsey, A.H. (2004). A History of Sociology in Britain: Science, Literature and Society. Oxford: Oxford University Press.

Hobsbawm, E. (1994). The Age of Extremes: The Short Twentieth Century, 1914-1991. London: Michael Joseph.

Macfarlane, A.D. (2009). Filmed interviews with leading thinkers. [website]. Available at: www.alanmacfarlane.com/ancestors/audiovisual.html.

Morgan-Brett, B. (2014). Teach with Pioneers. UK Data Service, Colchester: University of Essex. Available at: https://www.ukdataservice.ac.uk/teaching-resources/pioneers/ teach-with-pioneers.aspx.

Phillipson, C., \& Thompson, P. (2008). Whither Community Studies? A special issue on researching community studies, past and present. International Journal of Social Research Methodology, Theory and Practice, 11(2).

Savage, M. (2005). Working-Class Identities in the 1960s: Revisiting the Affluent Worker Study. Sociology, 39(5), 929-946. Dor:10.1177/0038038505058373.

Savage, M. (2010). Identities and Social Change in Britain since 1940: The Politics of Method. Oxford: Oxford University Press.

Stacey, M (1960) Tradition and Change: A Study of Banbury. Oxford University Press. Oxford.

Thompson, P. (1975). The Edwardians: The Remaking of British Society. London: Routledge.

Thompson, P. (2000). Re-using Qualitative Research Data: a Personal Account. [50 paragraphs]. Forum Qualitative Sozialforschung / Forum: Qualitative Social Research, 1(3), Art. 27, www.nbn-resolving.de/urn:nbn:de:0114-fqs0003277.

Thompson, P. (2004). Pioneering the life story method. International Journal of Social Research Methodology, 7(1), 81-84. DOI:10.1080/13645570310001640671.

Thompson, P. (with Bornat, J.) (2017). Voice of the Past, $4^{\text {th }}$ Edition. New York: Oxford University Press.

Thompson, P. (2019). Pioneers of Social Research, 1996-2018. [data collection]. 4th Edition. UK Data Service. SN: 6226, DoI:10.5255/UKDA-SN-6226-6.

Thompson, P., \& Corti, L. (Eds.) (2004). Celebrating classic sociology: Pioneers of contemporary British Qualitative Research, International Journal of Social Research Methodology, 7(1), 5-10. DOI:10.1080/0961452032000170596. 
Thompson, P., Plummer, K., \& Demireva, N. (forthcoming, 2020). Pioneering Social Research. Bristol: Policy Press.

Townsend, P. (1962). The Last Refuge, A Survey of Residential Institutions and Homes for the Aged in England and Wales. London: Routledge and Kegan Paul.

Townsend, P. (1979). Poverty in the United Kingdom. London: Allen Lane.

UK Data Archive (2015). Qualitative Data Ingest Processing Procedures. Colchester: University of Essex. Available at: https://dam.data-archive.ac.uk/controlled/cdog3-qua litativedatacollectioningestprocessingprocedures_08_oow.pdf. 